\title{
Prevenção do HIV sob o olhar de mulheres indígenas potiguaras*
}

HIV prevention under the view of indigenous women from the Potiguara tribe

Prevención del VIH según la perspectiva de mujeres de la tribu indígena potiguara

\section{Rafaela Gerbasi Nóbrega ', Natalia Aparecida de Oliveira II, Édija Anália Rodrigues de Lima, ${ }^{\text {III }}$ Ana Cristina de Oliveira e Silva ${ }^{\mathrm{IV}}$, Sandra Aparecida de Almeida ${ }^{\mathrm{v}}$, Jordana de Almeida Nogueira VI}

\begin{abstract}
Resumo: Objetivo: analisar o modo como a prevenção da infecção pelo vírus da imunodeficiência humana (HIV) se configura sob o olhar de mulheres da etnia potiguara. Método: estudo qualitativo, que envolveu 256 mulheres, procedentes de três aldeias indígenas da Paraíba-Brasil. As informações foram coletadas em 2015, por meio do Teste de Associação Livre de Palavras e entrevista semiestruturada. O corpus foi analisado a partir da Classificação Hierárquica Descendente, Análise de Conteúdo e Análise de Similitude. Resultados: foram identificadas três classes de conteúdos relacionados à prevenção do HIV: "Vulnerabilidade à infecção pelo HIV"; "Medidas protetivas"; e "Necessidade de educação em saúde”. A palavra "preservativo" ocupou a posição central na análise de similitude. Conclusão: embora reconheçam os meios de prevenção do HIV, há dificuldade para exercitar práticas sexuais protegidas. Tal condição é atravessada pelas desigualdades social e de gênero, extensivas à realidade das mulheres não indígenas.
\end{abstract}

Descritores: Saúde de populações indígenas; Síndrome de imunodeficiência adquirida; HIV; Saúde da mulher; Prevenção de doenças

\footnotetext{
* Extraído da tese "Do mundo para a tribo: a aids sob o olhar de mulheres de etnia potiguara”, Programa de Pós-Graduação em Enfermagem, Universidade Federal da Paraíba, 2016.

I Fisioterapeuta. Doutora em Enfermagem. Docente Centro Universitário de João Pessoa. João Pessoa, PB, Brasil, e-mail: rafaelagerbasi@yahoo.com.br e orcid: https://orcid.org/0000-0002-1786-9613.

II Enfermeira. Bacharelado e Licenciatura em Enfermagem. Universidade Federal da Paraíba, João Pessoa, PB, Brasil, e-mail: nataliaaparecida3@hotmail.com e orcid: https://orcid.org/0000-0002-0428-7008.

III Enfermeira. Mestre em Enfermagem. Professor Adjunto II da Unidade Acadêmica de Enfermagem, do Centro de Educação e Saúde da UFCG, Cuité, PB, Brasil, e-mail: edijaprof@hotmail.com e orcid: https://orcid.org/0000-0003-1055-2303.

${ }^{\text {IV }}$ Enfermeira. Doutora em Ciências da Saúde. Professor Adjunto II do Departamento de Enfermagem em Clínica, do Centro de Ciências da Saúde da UFPB, João Pessoa, PB, Brasil, e-mail: anacris.os@gmail.com e orcid: https://orcid.org/0000-0001-8605-5229.

${ }^{v}$ Doutora em Enfermagem. Professor Adjunto do Departamento de Enfermagem em Saúde Coletiva, do Centro de Ciências da Saúde da UFPB, João Pessoa, PB, Brasil, e-mail: sandraalmeida124@gmail.com e orcid: https://orcid.org/0000-0002-2183-6769

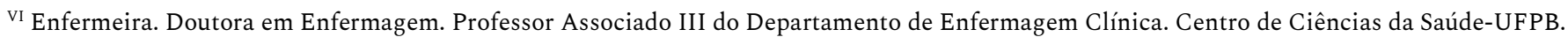
João Pessoa, PB, e-mail: jalnogueira31@gmail.com e orcid: https://orcid.org/0000-0002-2673-0285.
} 


\begin{abstract}
Objective: to analyze the way in which the prevention of infection by the human immunodeficiency virus (HIV) is configured under the view of women from the Potiguara ethnic group. Method: a qualitative study involving 256 women from three indigenous villages in Paraíba-Brazil The information was collected in 2015, through the Free Word Association Test and semi-structured interviews. The corpus was analyzed from the Descending Hierarchical Classification, Content Analysis, and Similitude Analysis. Results: three classes of content related to HIV prevention were identified: "Vulnerability to HIV infection"; "Protective measures"; and "Need for health education". The word "condom" occupied the central position in the similarity analysis. Conclusion: although they recognize the means for preventing HIV, it is difficult to perform protected sexual practices. Such condition is crossed by social and gender inequalities, which extend to the reality of nonindigenous women.
\end{abstract}

Descriptors: Health of indigenous populations; Acquired immunodeficiency syndrome; HIV; Women's health; Prevention of diseases

Resumen: Objetivo: analizar de qué manera se configura la prevención de la infección por el virus de la inmunodeficiencia humana (VIH) según la opinión de mujeres de la etnia potiguara. Método: estudio cualitativo en el que participaron 256 mujeres, procedentes de tres aldeas indígenas de Paraíba-Brasil. Los datos se recolectaron en el año 2015, por medio del Test de Libre Asociación de Palabras y de entrevistas semiestructuradas. El corpus se analizó a partir de la Clasificación Jerárquica Descendente, del Análisis de Contenido y del Análisis de Similitud. Resultados: se identificaron tres clases de contenidos relacionados con la prevención del VIH: "Vulnerabilidad ante la infección por VIH"; "Medidas de protección"; y "Necesidad de educación en salud". La palabra "preservativo” ocupó la posición central en el análisis de similitud. Conclusión: aunque reconocen los medios para prevenir el VIH, las mujeres tienen dificultades para llevar adelante prácticas sexuales protegidas. Dicha condición se ve atravesada por desigualdades sociales y de género, extensivas a la realidad de las mujeres no indígenas.

Descriptores: Salud de poblaciones indígenas; Síndrome de inmunodeficiencia adquirida; VIH; Salud de la mujer; Prevención de enfermedades

\title{
Introdução
}

Nas últimas décadas, as mudanças ocorridas no curso da epidemia ocasionada pelo vírus da imunodeficiência humana (HIV) conferiram-lhe distintas configurações. Se inicialmente a infecção pelo HIV constituía-se essencialmente um problema individual, abordado a partir da perspectiva biomédica e comportamental, a crescente atenção dada às suas dimensões socioculturais levou a uma compreensão mais ampliada dos diversos e complexos fatores relacionados à dinâmica da epidemia. A convivência com a infecção colocou em evidência a inabilidade da sociedade para lidar com as desigualdades sociais, dissimetria de gênero, desequilíbrios de poder, diferenças étnicas e culturais. ${ }^{1}$ Tal conjuntura, alinhada aos Objetivos 
3 | Nóbrega RG, Oliveira NA, Lima EAR, Silva ACO, Almeida SA, Nogueira JA

de Desenvolvimento Sustentável (ODS), impulsionou diretrizes globais, solicitando maior focalização nos grupos populacionais desproporcionalmente afetados pela epidemia, recomendando abordagens preventivas integradas e culturalmente competentes. ${ }^{1-2}$

Globalmente, destaca-se o acometimento de mulheres jovens, adolescentes e grupos com pouca ou nenhuma proteção social. Do total de 36,9 milhões de pessoas vivendo com o vírus no mundo, 18,8 milhões são mulheres. ${ }^{2-3}$ Embora se observe na última década, redução de $25 \%$ de novas infecções entre mulheres jovens de 15 a 24 anos, permanece inaceitável a ocorrência semanal de 6 mil novas infecções nesse grupo. ${ }^{1}$

No Brasil, entre 2007 e junho de 2019, foram notificadas 300.496 novas infecções pelo HIV, sendo 207.207 (69\%) em homens e 93.220 (31\%) em mulheres. A maior concentração de casos foi observada nos indivíduos com idade entre 20 e 39 anos, em ambos os sexos, correspondendo a $68,6 \%$ no sexo masculino e $57,4 \%$ no sexo feminino. Entre as mulheres, a categoria mais prevalente de transmissão $(86,5 \%)$ foi a sexual. ${ }^{4} \mathrm{Na}$ Paraíba, no mesmo período, foram notificados 5.451 casos de HIV, e a razão entre os sexos masculino e feminino foi de $2,4 .^{5}$

Como ferramenta complementar ao enfrentamento dessa epidemia, foi instituída a estratégia de "Prevenção Combinada", que faz uso simultâneo de diferentes abordagens de prevenção, abrangendo a biomédica, comportamental e socioestrutural, visando responder às necessidades específicas de determinados públicos. ${ }^{6}$ A combinação dessas ações amplia as possibilidades de o indivíduo se prevenir contra o vírus, oferecendo alternativas de maior alcance às populações vulneráveis. Dentre outras, prevê ações voltadas às condições socioculturais que influenciam diretamente a vulnerabilidade de indivíduos ou grupos específicos ao HIV, envolvendo preconceito, estigma, discriminação ou qualquer outra forma de alienação dos direitos e garantias fundamentais à dignidade humana.

Reconhecendo a existência de múltiplos pontos de intersecção entre as causas subjacentes da infecção por HIV, coloca-se como desafio a indução de abordagens preventivas, que leve em 
Prevenção do HIV sob o olhar de mulheres indígenas potiguaras | 4

conta os aspectos socioculturais que circundam o universo feminino. Determinações históricoculturais, valores morais, dificuldade em negociar práticas sexuais seguras, acesso restrito aos serviços de saúde e medidas de proteção, particularizam as desigualdades de gênero e a crescente violência contra as mulheres. ${ }^{7}$

Por sua vez, em se tratando da população indígena, as ações de prevenção do HIV requerem um olhar e tratamento cuidadosos para que as especificidades culturais sejam respeitadas. Devem incorporar na sua programação as representações indígenas sobre saúde, doença e estratégias de cura, adaptando-as às suas práticas sanitárias de modo a torná-las culturalmente adequadas a cada grupo étnico. ${ }^{8}$ Estima-se, no Brasil, a existência de 896 mil indivíduos indígenas, de 305 etnias distintas, sendo identificadas 274 línguas, o que revela grande diversidade sociocultural. ${ }^{9}$ Algumas etnias permanecem intocadas, sem convívio com a sociedade. Contudo, várias tribos sofreram influência intercultural decorrente da aproximação com os centros urbanos, o que cooperou para a disseminação de doenças e infecção pelo HIV..$^{10}$

O perfil da epidemia nesse grupo é pouco conhecido. Segundo registros do Sistema de Notificação de Agravos de Notificação, o percentual de casos de HIV em indígenas, no decorrer de 2007 a junho de 2019, correspondeu a 0,4\% dos casos encontrados na população em geral. No entanto, dados mostram que a infecção tem se concentrado entre indígenas residentes em áreas urbanas e em mulheres jovens. ${ }^{10}$ Nesse contexto, a vulnerabilidade feminina, muitas vezes, é peculiar aos valores culturais, vivenciando tradições como o patriarcado, machismo e rituais religiosos que potencializam as situações de risco a que estão expostas. ${ }^{11}$

Nessa vertente, que coloca a condição da mulher como centro de debate e reflexão, merece destaque quão complexas e diversificadas se apresentam as demandas dessa população. $O$ desafio mais urgente caracteriza-se pela adaptação das políticas e práticas em saúde, de modo a torná-las culturalmente adequadas a cada grupo étnico, bem como a compreensão de suas especificidades dentro da alteridade cultural que as diferencia. 
5 | Nóbrega RG, Oliveira NA, Lima EAR, Silva ACO, Almeida SA, Nogueira JA

Logo, torna-se pertinente, no campo da saúde indígena, discutir aspectos relacionados à prevenção do HIV para estruturar e implementar ações realmente competentes no manejo da infecção. Desse modo, pretende-se dar visibilidade à expressão dessa problemática no povo potiguara visto a escassez de produções com essa perspectiva. Diante desses apontamentos iniciais, este estudo tem como questões de pesquisa: o que as mulheres indígenas pensam a respeito da prevenção do HIV? A prevenção do HIV é influenciada por peculiaridades étnicas?

Consequentemente, a presente discussão torna-se relevante para o campo da enfermagem, sobretudo para conhecer particularidades que norteiam as formas de prevenção dessa infecção, clarificando a necessidade de utilização de códigos culturais indígenas para uma melhor eficácia dessas ações. Portanto, este estudo objetivou analisar o modo como a prevenção do HIV se configura sob o olhar de mulheres da etnia potiguara.

\section{Método}

Estudo descritivo, de natureza qualitativa, envolvendo 256 índias, procedentes das três aldeias pertencentes à área contígua ao município de Rio Tinto/ Paraíba: aldeia Mont-Mór, Jaraguá e Silva de Belém. As duas primeiras são mais populosas e próximas à região urbana, e a terceira situa-se em área rural, com maior vulnerabilidade econômica. As referidas aldeias integram o Distrito Sanitário Especial Indígena Potiguara (DSEI-28), que representa um dos 34 DSEI distribuídos pelo Brasil. Trata-se de uma unidade gestora descentralizada do Subsistema de Atenção à Saúde Indígena, integrada ao Sistema Único de Saúde (SUS), cujo modelo de organização de serviços é orientado para um espaço etnocultural dinâmico, geográfico, populacional e administrativo bem delimitado. Cada aldeia/comunidade conta com a atuação do Agente Indígena de Saúde (AIS), cujas atividades estão vinculadas a um posto de saúde. É oportuno ressaltar que o povo potiguara se comunica em português, apesar de preservarem entre eles a comunicação na língua tupi. 
Prevenção do HIV sob o olhar de mulheres indígenas potiguaras $\mid 6$

O cálculo amostral baseou-se na totalidade de mulheres com idade entre 18 e 65 anos residentes nas aldeias $(\mathrm{N}=739)$, o qual admitiu um nível de significância de $5 \%$, sob o nível de confiança de $95 \%$ e um valor antecipado de proporção (p) igual a 0,50. Elegeu-se como critério de amostragem a partilha proporcional, considerando a população feminina de cada aldeia: 158 mulheres na aldeia Mont-Mór, 64 na Jaraguá e 34 na Silva de Belém. As participantes foram selecionadas pela amostragem não probabilística, por conveniência, adotando-se como critérios de inclusão: ser mulher da etnia potiguara; de 18 a 65 anos; e residir no local de estudo. Foram excluídas mulheres acometidas por problemas de saúde, que apresentavam dificuldade na comunicação.

Para obtenção do material empírico, foram utilizadas duas técnicas. Inicialmente, empregou-se o Teste da Associação Livre de Palavras (TALP), tendo com estímulo indutor a expressão "prevenção do HIV". Essa técnica é utilizada para a obtenção de dados que viabilizam informações projetivas referentes aos processos mentais dos participantes. ${ }^{12}$ Sequencialmente, utilizou-se um roteiro de entrevista semiestruturado, com quesitos sobre identificação (nome da aldeia, idade e conjugalidade), e perguntas que abordaram informações, atitudes e dificuldades relacionadas aos aspectos preventivos do HIV.

As entrevistas ocorreram entre março e setembro de 2015, realizadas por uma equipe composta por cinco componentes, incluindo a pesquisadora responsável, sendo uma doutoranda em Enfermagem, dois graduandos em Fisioterapia e duas enfermeiras integrantes do Núcleo de Estudos em HIV e AIDS, Saúde e Sexualidade (NEHAS) da Universidade Federal da Paraíba, todos devidamente treinados e qualificados.

Cada participante foi interpelada por um entrevistador que se apresentou como pesquisador, convidou-a para participar da entrevista, forneceu informações sobre a natureza e objetivos do estudo, e solicitou a sua permissão para participação mediante a assinatura do Termo de Consentimento Livre e Esclarecido. As entrevistas foram audiogravadas, com duração 
7 | Nóbrega RG, Oliveira NA, Lima EAR, Silva ACO, Almeida SA, Nogueira JA

média de 30 minutos, e ocorreram em distintos espaços (residências, serviços de saúde, escolas e ocas), considerando a comodidade da participante. Para isso, buscaram-se ambientes reservados, com o mínimo de ruído, contando com a presença, apenas, do entrevistador e da participante.

Os resultados transcritos compuseram o corpus, o qual foi submetido a um refinamento para exclusão de repetições vocabulares, agrupamento das palavras por aproximação semântica e composição de um dicionário. Dois pesquisadores validaram o dicionário. Sequencialmente, as informações foram processadas pelo software de Análise Textual IRaMuTeQ (Interface de $R$ pour les Analyses Multidimensionnelles de Textes et de Questionnaires-Versão 0.6 alpha 3), que classificou os segmentos de texto em função dos seus respectivos vocabulários gerando a Classificação Hierárquica Descendente $(\mathrm{CHD}) \cdot{ }^{13}$ Do total de 256 Unidades de Contexto Inicial (UCIs) presentes no corpus, foram retidas 522 Unidades de Contexto Elementar (UCEs), com aproveitamento de $74,6 \%$, originando classes de respostas sobre a prevenção do HIV, a partir do vocabulário e pelas variáveis que contribuíram na formação de cada classe, selecionadas de acordo com os valores do qui-quadrado $\left(X^{2}\right.$.

A análise interpretativa do corpus se deu pelo uso da Análise de Conteúdo, modalidade temática, ${ }^{14}$ que indicou convergência das características empíricas em torno de três temas, sendo denominados a posteriori como: Vulnerabilidade à infecção pelo HIV; Medidas protetivas; e Necessidade de educação em saúde. Adicionalmente, a conjuntura textual foi submetida à técnica de análise de similitude, que agrupou e organizou graficamente as palavras em função da sua frequência, possibilitando rápida identificação das concorrências e conexidade entre as palavras. ${ }^{13}$

O estudo respeitou a Resolução n ${ }^{\circ}$ 466/2012 do Conselho Nacional de Saúde e a Resolução 304/2000, no que diz respeito à temática especial “populações indígenas”, sendo aprovado pelo Conselho Nacional de Ética em Pesquisa - CONEP em 26/01/2015, sob o parecer n 975.370. Para garantir o sigilo das informações e anonimato das participantes, os depoimentos foram 
codificados pela letra "n” acrescida do underline e número arábico correspondente à ordem cronológica crescente da realização das entrevistas.

\section{Resultados e Discussão}

$\mathrm{Na}$ amostra pesquisada ( $\mathrm{n}=256)$, verificou-se predominância na faixa etária entre 30-45 anos (38,7\%), casadas/união estável (73,8\%), com até oito anos de estudo $(56,6 \%)$ e renda familiar de 1 a 2 salários mínimos $(67,2 \%)$.

$\mathrm{Na}$ análise do corpus, observa-se a partir do dendrograma (Figura 1) que a primeira partição originou 2 subgrupos. O primeiro subgrupo constituiu-se pela classe 1, denominada Vulnerabilidade à infecção pelo HIV. O segundo subgrupo foi composto pelas classes 2 e 3 , designadas, respectivamente, como Medidas protetivas e Necessidade de educação em saúde.

Figura 1 - Dendrograma referente à distribuição do vocabulário das classes segundo a Classificação Hierárquica Descendente. Rio Tinto - PB, Brasil (2018).

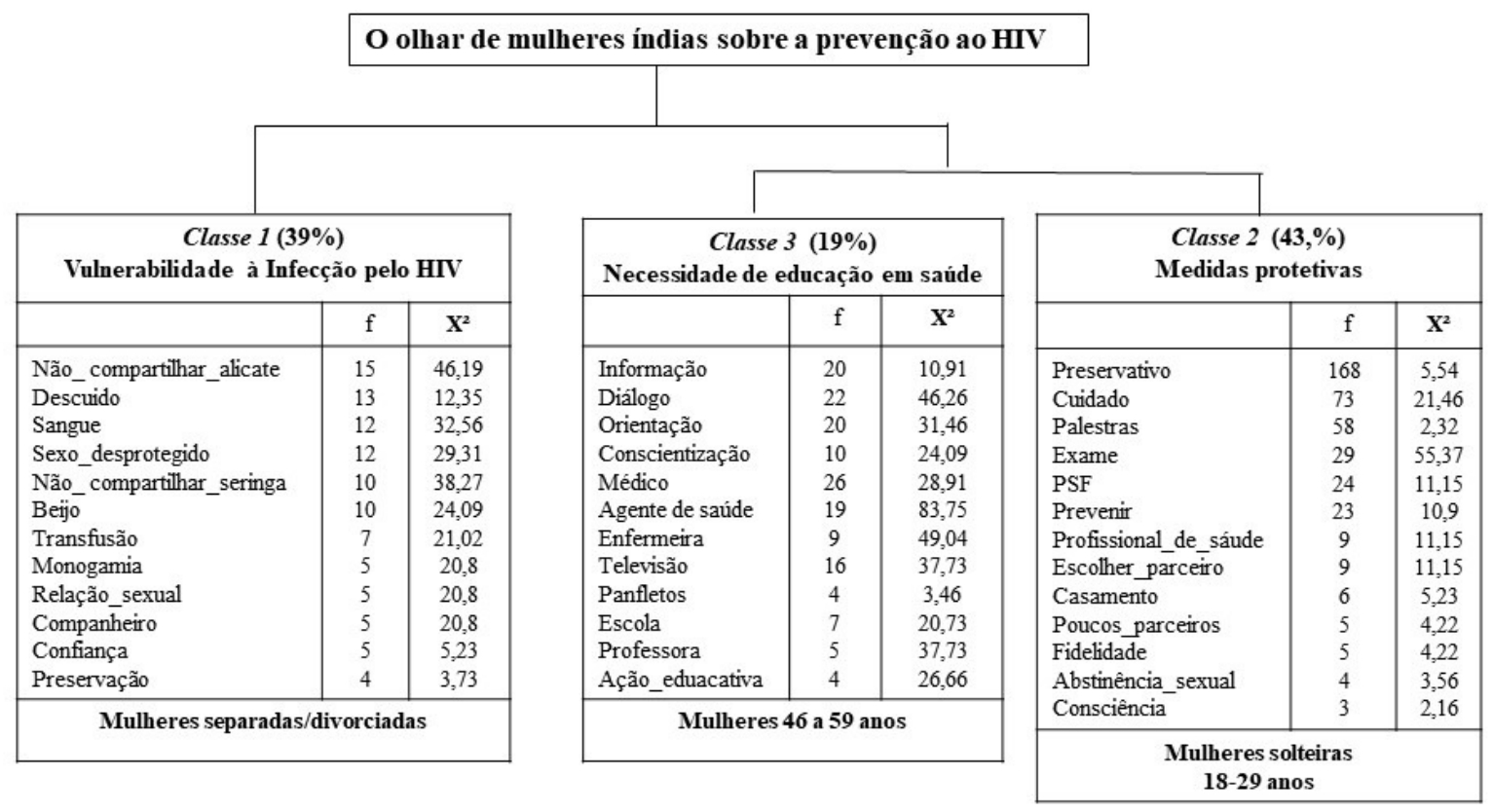

A classe 1 - Vulnerabilidade à infecção pelo HIV - concentrou 39\% das UCEs, sendo constituída predominantemente por mulheres separadas/divorciadas. Os conteúdos evidenciaram que as fragilidades na adoção de práticas preventivas estão relacionadas ao 
9 | Nóbrega RG, Oliveira NA, Lima EAR, Silva ACO, Almeida SA, Nogueira JA

descuido, ausência de preservação, ao compartilhamento de objetos pessoais (alicates de unha) ou mesmo advindas de transfusão e contato com sangue contaminado. A relação sexual, aliada à confiança no companheiro e à monogamia, perpetua práticas e comportamentos sexuais desprotegidos.

Nesse contexto, predominam concepções conservadoras, não muito diferentes das primeiras décadas da epidemia, em que o conhecimento acerca da infecção pelo HIV e as manifestações clínicas da síndrome reforçavam o discurso de responsabilização e culpabilização pelas atitudes negligentes adotadas pelas pessoas. Acredita-se que esse estigma se deveu às formas de transmissão do vírus e dos padrões sociais pré-epidemia, baseados na moral sexual e prescrição sobre o que seria o comportamento sexual adequado. ${ }^{7}$ Entretanto, parece que esse entendimento ainda é compartilhado nos dias atuais:

Eles pegam essa doença pelo próprio descuido. (n_157)

Não se preveniu e pegou a doença. (n_153)

Era para ter prevenido, escutado conselhos. (n_068)

Estudo etnográfico, desenvolvido com grupos indígenas habitantes do norte de Tocantins e sul do Maranhão, evidenciou que a ocorrência de doenças ou infecções transmitidas por via sexual foi reconhecida como produto de práticas individualizadas, estando o processo saúdedoença-enfermidade congruente aos contatos interétnicos. ${ }^{15}$ Contrair o HIV por meio da prática sexual parece depender mais da vontade e, portanto, implica mais culpabilidade. Observa-se, nos fragmentos de texto, a construção do mesmo repertório estigmatizante identificado em outros grupos sociais. A experiência de viver com HIV é vista por muitos como algo vergonhoso, conduzindo aos acometidos pelo vírus uma sensação de culpa e responsabilidade por não adotar medidas preventivas e, consequentemente, provocar a própria infecção. ${ }^{16}$ 
No entanto, na contemporaneidade, admite-se que a vulnerabilidade ao HIV se expressa de modo tridimensional. Desse modo, vai além da esfera individual, e se estende para o espaço social e programático ou político-institucional. ${ }^{17}$ Nessa perspectiva, se reconhece a corresponsabilização do indivíduo, sociedade e Estado sobre as possibilidades de exposição das pessoas ao vírus bem como ao posterior adoecimento.

Além do sexo, o contato com sangue advindo de ferimentos e transfusões também foi citado como meio de transmissão do HIV. Contudo, ainda permanecem informações distorcidas, traduzidas na afirmação de que a infecção pode ser adquirida pelo beijo.

O risco maior é na relação sexual, alicate de unha de outra pessoa, beijo. (n_154)

Dizem transmitir a doença por beijo, transfusão de sangue, manicure e relação sexual. (n_032)

As representações que os povos indígenas costumeiramente fazem sobre sangue, fluidos corpóreos, constituição da vida e propagação de doenças ainda requerem maiores investigações e estudos antropológicos. Algumas etnias utilizam objetos cortantes para escarificar a pele, retirar o sangue fraco e aplicar emplastro de ervas para receber forças das entidades espirituais. A depender da tribo, o uso da tatuagem definitiva é uma prática ritualística de pertencimento da cultura e história. Para além da intenção estética, são atribuídos significados de proteção divina e passagem para a vida adulta. ${ }^{18}$ No entanto, para outros povos, a exemplo dos indígenas timbiras, o sangue já é considerado uma substância eminentemente perigosa e transmissora de enfermidades. ${ }^{15}$

Por outro lado, ao citarem o beijo como forma de transmissão do vírus, descortinam as limitações de conhecimento acerca das possibilidades de contágio do HIV, o que ainda é comum em populações não indígenas. O ato de beijar, sobretudo na boca, foi referido como forma de 
11 | Nóbrega RG, Oliveira NA, Lima EAR, Silva ACO, Almeida SA, Nogueira JA

transmissão do vírus, apesar de a ciência ter demonstrado que a saliva não é reconhecida como meio de transmissão do HIV. ${ }^{19-20}$

Outro ponto relevante refere-se à confiança no parceiro como fator de proteção à infecção pelo HIV. Trata-se de uma problemática similar aos estudos com a população não indígena, conferindo um desafio para as políticas de controle do HIV, já que o conhecimento das mulheres sobre as formas de transmissão não lhes garante a incorporação de ações de prevenção do vírus.

A maioria pega (HIV) sem saber, são vítimas, confiaram no parceiro. Ninguém se importa com isso, importa o amor, a felicidade.(n_016)

É transmitida quando a gente se relaciona com uma pessoa que não conhece. (n_158)

Sempre pergunto ao meu marido se ele só vive comigo, ele responde que sim, por isso eu confio nele. (n_146)

As fragilidades das mulheres para lidar com as faces da vulnerabilidade ao HIV demandam superação, provinda do empoderamento. Entende-se que este deverá respaldar-se em estratégias políticas pautadas nas peculiaridades culturais de comunidades indígenas e não indígenas.

Nesse processo, é importante salientar que comumente o status sorológico dos parceiros é desconhecido ou discordante. Além disso, os intuitos reprodutivos, cuidados com a prevenção, alcance a elementos preventivos e predileção por práticas sexuais, por vezes, são desencontrados. Assim se expressa um horizonte diversificado de exposição ao HIV com chance de imprecisões nas práticas preventivas. ${ }^{21}$ Sobre esse prisma, novamente, vislumbra-se a necessidade emergente de reconhecer os elementos sociais e programáticos da vulnerabilidade por entender que os fatores conjunturais movem o indivíduo em seu cotidiano, e que o acesso aos cuidados ofertados pelas instituições demanda empenho e investimentos em ações 
preventivas. Entende-se que esses eixos interagem de forma dinâmica e são fundamentais para promover sustentabilidade de acesso a cuidados integrados com ênfase na prevenção.

Ao abordar as trajetórias de mulheres vivendo com HIV no Brasil, assinalou-se a importância de considerar os contextos de vida e enfrentamento feminino nas práticas de cuidado. Destacou-se, ainda, que estratégias direcionadas a uma epidemia concentrada podem levar à desatenção com populações consideradas não prioritárias. ${ }^{22}$

A classe 2 - Medidas protetivas - concentrou 43\% das UCEs, sendo representada predominantemente por mulheres solteiras, com idade entre 18 e 29 anos. Essa classe apresentou elementos relativos à necessidade de cuidado perante o sexo nas aldeias, que requerem, especialmente, ações de prevenção com enfoque para o uso de preservativo, escolha do parceiro ou mesmo abstinência sexual.

A gente deve se prevenir com preservativo. (n_069)

O companheiro não aceita ter relação sexual com preservativo, daí muitos problemas acontecem. (n_017)

Muitos acham que o preservativo atrapalha, principalmente os homens que não querem usar. (n_132)

Homem deseja a mulher sem preservativo. Quando a mulher diz você tem que usar preservativo, o homem diz não quero, mas a mulher tem que ter iniciativa, porque vai pegar essa doença. (n_020)

Mesmo reconhecendo a importância do preservativo, a baixa intenção de uso pelos seus parceiros acentua a vulnerabilidade dessas mulheres ao HIV e a outras ISTs. A rejeição ou pouca adesão ao preservativo, em virtude da crença sobre o seu efeito redutor do prazer sexual, aponta um padrão não exclusivo da cultura indígena. Por sua vez, indica poder de negociação limitado das mulheres quanto às práticas sexuais seguras, inclusive por aquelas que vivem com o 
13 | Nóbrega RG, Oliveira NA, Lima EAR, Silva ACO, Almeida SA, Nogueira JA

HIV. Diante dessas circunstâncias, é oportuno afirmar que os aspectos de gênero incrementam a vulnerabilidade feminina e têm repercussões negativas para a saúde de mulheres e de homens. ${ }^{23-24}$

Ainda que os estereótipos de gênero e as condições de vida prejudiquem a autonomia sexual feminina e ampliem a exposição ao HIV, o estigma associado à infecção coopera para ocultar as desigualdades de gênero, implicadas na vulnerabilidade da mulher ao vírus. Confrontar o estigma relativo ao acometimento de mulheres pressupõe mudanças micro e macroestruturais, bem como procedimentos culturais, com potencial para desfazer os estereótipos de gênero e expandir a autonomia sexual das mulheres. ${ }^{25}$ As restrições do poder de participação nas decisões sobre a vida sexual e reprodutiva, além das coerções emocionais, de caráter culturalmente determinado, interferem na prevenção do HIV entre as mulheres.

Ademais, sabe-se que, em algumas terras indígenas, as práticas sexuais extraconjugais são admitidas com naturalidade, estando relacionadas a situações prazerosas da convivência humana. Nos rituais festivos podem ocorrer relações extramatrimoniais, sendo o ciúme desaconselhado. ${ }^{15}$ No entanto, no contexto potiguara, tais condutas são interpretadas pelas mulheres índias como desrespeito, negligência quanto ao uso de preservativo e desatenção das esposas.

A maioria dos homens aqui não respeita as mulheres. Tem sua mulher, mas tem outra coisa por fora. A outra a gente não sabe o que faz, a gente sabe da gente. Se não querem usar preservativo com a esposa, que se previnam por fora. Nenhum vai dizer que vai trair. É por isso que o índice está cada vez maior aqui na aldeia. Tenho uma amiga que tem HIV. Ela pegou do marido. (n_122)

Tem que ter cuidado com o marido que pode ter relação sexual fora do casamento. Se desconfiar, tem que usar preservativo. (n_065)

Meu marido tem 64 anos, ele pode sair e encontrar uma pessoa com aids e trazer a doença para mim. (n_105) 
Embora o relato faça alusão à falta de respeito e traição dos maridos, emerge a discussão da poligamia indígena como uma prática corrente, reservada apenas aos homens. A transparência e a aceitação dessa condição por parte das mulheres têm raízes na cultura de algumas etnias. No caso dos potiguaras, a poligamia não é determinante da cultura local, mas a sua anuência por parte das mulheres está associada a situações de dependência financeira. A presente convicção diz respeito à hierarquização, subordinação, dominação e posição social dos homens nas aldeias indígenas. Em muitas etnias, o homem ocupa a posição de provedor da família, existindo uma tradição quanto à obediência e respeito ao marido por parte das suas mulheres, que reproduzem esse comportamento às demais gerações. ${ }^{26}$

Ao explorar alguns dos significados mais gerais da noção de negociação sexual, visualizase, com frequência, nas aldeias um conformismo da figura feminina, atribuindo para si a reponsabilidade de resguardar sua integridade com medidas cautelosas na escolha dos parceiros.

É preciso muito cuidado, principalmente na relação com o parceiro. Saber qual o tipo de pessoa que você está se relacionando. (n_070)

As mulheres deveriam se prevenir, não ter muitos parceiros, ter o seu par fixo.(n_105)

A gente deve escolher o parceiro que vai se relacionar. (n_069)

É para a pessoa usar o preservativo, a gente nunca sabe o dia de amanhã, se o parceiro é correto. (n_093)

No Brasil, as relações heterossexuais são pautadas em valores patriarcais, em que se evidencia uma dissimetria de papéis entre homens e mulheres. Tais aspectos associam-se a estereótipos socioculturais que orientam o comportamento feminino e moldam as desigualdades e violência de gênero. Esse tipo de violência vem se expressando como um crítico problema de 
15 | Nóbrega RG, Oliveira NA, Lima EAR, Silva ACO, Almeida SA, Nogueira JA

saúde, que se perpetua pela invisibilidade e sub-registro. ${ }^{27-28}$ Assemelham-se ao padrão normativo de comportamento sexual do modelo ocidental hegemônico, no qual o casamento é monogâmico, estando associado à fidelidade conjugal. Apesar disso, mostram-se atentas à exposição à IST e ao uso do preservativo.

As mulheres potiguaras reforçam condutas seletivas e cuidadosas, perante relacionamentos considerados estáveis. Além disso, sinalizam preocupação com as jovens, que exercem práticas sexuais em outros formatos de relacionamentos.

Aqui na aldeia tem muitas garotas jovens que se envolvem com vários parceiros, mas ninguém sabe se alguma delas tem aids, porque o que falta aqui são os testes de HIV. Meninas de 11 anos, 12 anos, 13 anos, estão soltas e são vulneráveis para se contaminar com a aids. (n_071)

Para algumas tribos indígenas, a menarca sinaliza que a menina iniciou a vida sexual, logo deverá apontar o homem com quem se relacionou para que o dote seja cobrado. Além disso, as mulheres solteiras admitem uma postura social, na qual mantêm um comportamento sexual livre e são respeitosamente reconhecidas na aldeia. ${ }^{15}$ Porém, na cultura potiguara, tais práticas não são consentidas.

No cenário indígena em pauta, expressa-se reconhecimento da vulnerabilidade de mulheres muito jovens à IST, requerendo o diagnóstico precoce, por meio da oferta regular de testes como o anti-HIV. É sabido que a expansão da oferta de testagem se configura como uma importante intervenção técnica empregada com a finalidade de desacelerar a ocorrência de novas infecções pelo $\mathrm{HIV} .{ }^{27} \mathrm{Na}$ medida em que se antecipa a identificação de infecção pelo HIV, podem-se intensificar as medidas de prevenção da sua propagação, bem como otimizar cuidados para ampliar a expectativa de vida de pessoas vivendo com o vírus. 
Para além desses aspectos, outros entendimentos desencadeados por fatores culturais podem se estender à condição de saúde, por exemplo, a crença de que sua condição étnica lhe confere proteção e imunidade a danos físicos.

Ele foi contaminado e a esposa dele pegou também. Nós dizíamos para a esposa dele ter cuidado e ela dizia que não pegava aids, porque era índia. (n_017)

Esse posicionamento não pegava aids porque era índia põe em relevo as fortes influências da cultura potiguara. Ainda que haja uma proximidade das aldeias com a cultura ocidental, o modo de ver e reagir à epidemia do HIV é dimensionado pelos costumes, crenças e práticas que ainda traçam a identidade desse grupo. Tais concepções podem se constituir obstáculos, impedindo ou dificultando o acesso aos serviços de testagem sorológica, prevenção e cuidados de saúde. ${ }^{10}$

Logo, o desenvolvimento de ações preventivas deve focalizar e considerar as representações, valores e práticas relativas ao adoecer. No caso das populações indígenas, o simbolismo da "mulher guerreira" atribuído à índia potiguara subjaz um entendimento para algumas delas de sangue forte que possibilita uma condição de imunidade ao HIV por parte desse grupo. Essa condição de invulnerabilidade aos agravos diz respeito aos constructos de pertença social e representa heranças de sua ancestralidade.

Destaca-se, portanto, a importância deste debate na construção de estratégias políticas que incorporem elementos subjetivos e produzam impacto em decisões individuais e íntimas. Que os processos educativos não se restrinjam apenas às informações de cunho científico, mas que façam sentido para os indígenas e apresentem aderências ao seu contexto cultural.

De modo geral, no cenário brasileiro, o conhecimento insuficiente sobre a cultura dos povos indígenas é uma realidade dos distritos sanitários indígenas. No tocante ao enfrentamento das ISTs, essa problemática é mais expressiva em virtude da desarticulação das 
17 | Nóbrega RG, Oliveira NA, Lima EAR, Silva ACO, Almeida SA, Nogueira JA

ações com a cultura local. Esse fato contribui para o alargamento da vulnerabilidade, uma vez que o próprio subsistema de saúde indígena se mostra despreparado para dialogar de modo intercultural sobre um tema delicado, multifacetado e de difícil abordagem. ${ }^{15}$

A classe 3 - Necessidade de educação em saúde - reteve 19\% das UCEs, sendo constituída predominantemente por mulheres solteiras com idade entre 46 e 59 anos. Segundo os seus elementos integrantes, a prevenção do HIV dentro das aldeias requer socialização de informações por meio de ações educativas, ampliação do diálogo e orientações. Tais recursos, mediados por profissionais experientes (médicos, enfermeiros, agentes de saúde, professores), podem promover a conscientização da população indígena quanto às medidas de prevenção ao HIV.

A prevenção ajuda. Se tivessem mais ações de prevenção, para informar, palestras na comunidade, seria bom. Sinto falta. (n_071)

Os agentes de saúde explicam para gente que é uma doença e que ela não tem cura e que se não se cuidar, pode levar à morte. (n_012)

Buscar informações nos postos de saúde, gente próxima que pode informar melhor e nas escolas. (n_069)

Na escola, a gente trabalha [prevenção], mas é muito amplo e precisa de um reforço maior. (n_044)

A busca por informações sobre os mecanismos de prevenção ao HIV também ecoou nos depoimentos. É uma necessidade premente, considerando os limitados recursos e parcas iniciativas nas aldeias. Estudo de revisão integrativa destacou que as ações de prevenção ao HIV direcionadas às tribos indígenas têm sido focalizadas, desenvolvidas por meio de campanhas educativas, aconselhamento, testagem anônima e abordagem psicossocial. Entretanto, evidenciaram dificuldades na implementação dessas ações, em virtude dos diferenciais 
etnoculturais, convenções sociais, obstáculos linguísticos e de seus sistemas tradicionais de cura. $^{10}$

Diante das referidas demandas por maiores informações acerca da prevenção ao HIV, acredita-se que os profissionais atuantes na saúde e educação possam atentar para o agendamento de encontros de cunho educativo que abordem, com clareza e criatividade, as problemáticas que cercam o HIV nas aldeias.

A escassez de ações preventivas para o HIV nas aldeias potiguaras é um fator significativo de insatisfação entre as mulheres, que passam a emitir depoimentos condizentes com as lacunas ora apontadas.

Os jovens estão desenvolvendo mais cedo e não estão tendo acompanhamento, orientações para combater essa doença. (n_044)

Cumpre destacar que a falta de acompanhamento e informações para os jovens foi referida por mulheres pertencentes às duas maiores aldeias desta investigação: Monte-Mór e Jaraguá, que se configuram como aquelas que detêm maior população indígena adstrita.

Dito isso, evidencia-se a necessidade de implementação de ações relativas à prevenção do HIV nas aldeias, com enfoque em ações educativas que perpetuem informações, respeitando as crenças de cada etnia indígena. Tal medida possivelmente mobilizará iniciativas para o desenvolvimento de competências profissionais pautadas na interculturalidade ${ }^{29}$ como também no encorajamento para o autocuidado nas aldeias.

A análise de similitude descrita na Figura 2 apresentou as conexões estabelecidas entre os elementos do corpus textual, a interconexão entre as palavras, bem como o nível de relação entre elas. A leitura cognitiva da árvore possibilitou observar que o elemento preservativo ocupou a centralidade do diagrama, caracterizando-se como recurso principal de prevenção ao HIV para as mulheres indígenas. A palavra central apresentou forte relação com o cuidado. Isso faz 
19 | Nóbrega RG, Oliveira NA, Lima EAR, Silva ACO, Almeida SA, Nogueira JA

sentido, já que o meio de prevenção pelo uso do preservativo requer um cuidado consigo, no contato com o outro, um sentido de preservação da vida.

No mesmo espaço gráfico, a palavra palestra apresenta-se como estratégia de promoção de conscientização para o uso do preservativo. Ainda na parte superior direita da rede de conexões, está presente o elemento confiança como um dispositivo oponente ao uso de preservativos. Em destaque adjacente, há traços leves que conectam o preservativo à escola, caracterizando-se como espaço educativo promissor, quando atrelado à figura do professor.

Figura 2 - Análise de Similitude - prevenção do HIV segundo mulheres da etnia potiguara Rio Tinto-PB (2018).

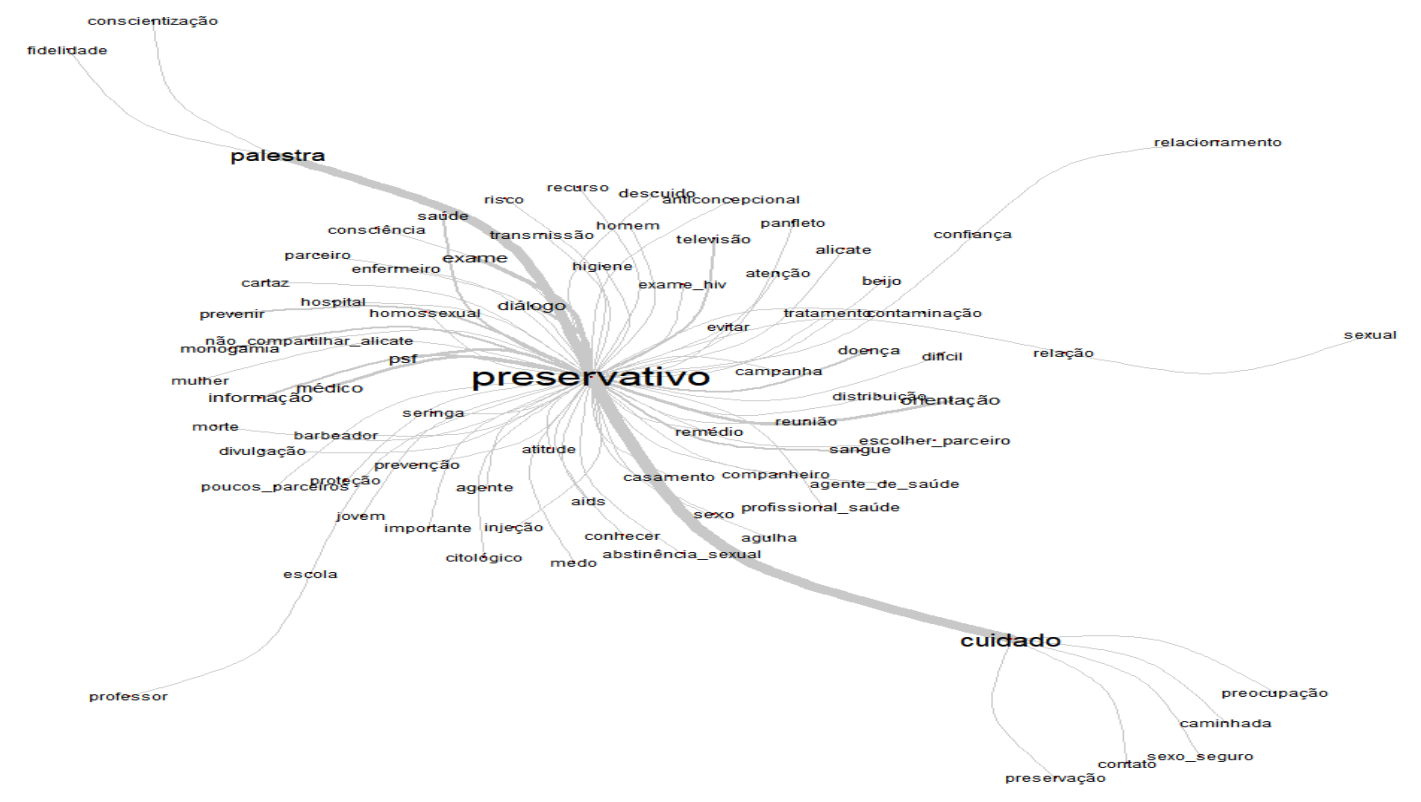

\section{Conclusão}

As mulheres potiguaras configuram a prevenção ao HIV a partir do reconhecimento dos riscos de infecção, das desafiadoras possibilidades de enfrentamento, bem como pela nítida compreensão de que o preservativo se apresenta como um recurso importante para conferir proteção ao HIV.

Compreendem, ainda, que as discussões e esclarecimentos que circundam a infecção pelo HIV requerem atitudes de cuidado, perpassadas pelo acesso seguro a informações e diálogo efetivo, estabelecido entre os parceiros sexuais e com os profissionais da saúde e educação. 
Embora exista clareza quanto aos riscos de infecção, há dificuldade para exercitar práticas sexuais protegidas em virtude de barreiras objetivadas pela resistência do parceiro ao uso do preservativo; desconfiança de relacionamentos extraconjugais; e dificuldade de negociar o emprego do preservativo no cotidiano. Esses entraves estão atravessados pelas questões de desigualdade social e de gênero extensivas à realidade das demais mulheres não indígenas.

As limitações do estudo estão relacionadas ao fato de se considerar uma realidade específica. Mesmo que tais achados se assemelhem aos identificados na população em geral, não há como universalizá-los, dadas as variações culturais dos povos indígenas.

Acredita-se que o presente estudo possa instigar o desenvolvimento de pesquisas que focalizem os contextos sociais e culturais, nos quais as interações e comportamentos têm lugar e adquirem significados peculiares. Reforça, ainda, a urgência de respostas efetivas tanto no que se refere às formas de prevenção ao HIV, ao empoderamento desse grupo a atitudes apropriadas de cuidado e proteção e à capacitação dos profissionais de saúde, como à conformação e às motivações e condutas sexuais dentro da conjuntura indígena.

\section{Referências}

1. Joint United Nations Program on HIV/AIDS (UNAIDS). Global AIDS monitoring 2020 [Internet]. 2019 [cited 2020 Feb 20]. Available from: http://www.unaids.org/sites/default/files/media_asset/global-aidsmonitoring_en.pdf

2. Oldenburg CE. Integrated HIV prevention and care for key populations. Lancet HIV. 2019;6(5): 270-1. doi: http://dx.doi.org/10.1016/S2352-3018(19)30042-6

3. Brandão BMGM, Pereira VMAO, Góis ARS, Silva CRL, Abrão FMS. Social representations of the nursing team in the patient with HIV/AIDS: an integrating review. Rev Enferm UFPE On Line [Internet]. 2017 [cited 2018 Oct 15];11(2):625-33. Available from: https://periodicos.ufpe.br/revistas/revistaenfermagem/article/view/11982

4. Ministério da Saúde (BR). Boletim Epidemiológico de HIV/AIDS 2019 [Internet]. 2019 [acesso em 2020 jan 11]. Disponível em: http://www.aids.gov.br/pt-br/pub/2019/boletim-epidemiologico-de-hivaids-2019

5. Ministério da Saúde (BR), Secretaria de Vigilância em Saúde, Departamento de Doenças de Condições 
Crônicas e Infecções Sexualmente Transmissíveis. Indicadores e dados básicos do HIV/AIDS nos municípios brasileiros [Internet]. 2019 [acesso em 2020 fev 21]. Disponível em: http://indicadores.aids.gov.br/

6. Ministério da Saúde (BR). Diretrizes para organização do CTA no âmbito da Prevenção Combinada e nas Redes de Atenção à Saúde. Brasília (DF): Ministério da Saúde; 2017.

7. Ceccon RF, Meneghel SN. Iniquidades de gênero: mulheres com HIV/Aids em situação de violência. Physis. 2017;27(4):1087-100. doi: https://doi.org/10.1590/s0103-73312017000400012

8. Ministério da Saúde (BR), Fundação Nacional de Saúde. Política Nacional de Atenção à Saúde dos Povos Indígenas. 2ª ed. Brasília (DF): Ministério da Saúde; 2002.

9. Fundação Nacional do Índio (BR). O Brasil indígena (IBGE) [Internet]. 2011 [acesso em 2018 out 15]. Disponível em: http://www.funai.gov.br/index.php/indios-no-brasil/o-brasil-indigena-ibge

10. Nóbrega RG, Nogueira JA, Almeida SA, Marcolino ABL, Cananéa JNA, Bezerra VP. Saúde indígena em tempos de Aids: revisão integrativa. Online Braz J Nurs [Internet]. 2015 [cited 2019 Oct 15];14(2):20516. Available from: http://www.objnursing.uff.br/index.php/nursing/article/view/5217

11. Harrison A. HIV prevention and research considerations for women in sub-saharan Africa: moving toward biobehavioral prevention strategies. HHS Public Access. 2014;18(3):17-24.

12. Tavares DWS, Brito RC, Córdula ACC, Silva JT, Neves DAB. Protocolo verbal e teste de associação livre de palavras: perspectivas de instrumentos de pesquisa introspectiva e projetiva na ciência da informação. PontodeAcesso. 2014;8(3):64-79. doi: http://dx.doi.org/10.9771/1981-6766rpa.v8i3.12917

13. Camargo BV, Justo AM. Tutorial para uso do software IRaMuTeQ [Internet]. Florianópolis: Laboratório de Psicologia Social da Comunicação e Cognição; 2018 [acesso em 2018 out 31]; Disponível em: http://www.iramuteq.org/documentation/fichiers/tutoriel-portugais-22-11-2018

14. Bardin L. Análise de conteúdo. São Paulo: Edições 70; 2016.

15. Ávila T. Cultura, sexualidade e saúde indígena: etnografia da prevenção das DST/Aids nos povos Timbira do Maranhão e do Tocantins. In: Teixeira CC, Garnelo L, organizadoras. Saúde indígena em perspectiva: explorando suas matrizes históricas e ideológicas. Rio de Janeiro: Fiocruz; 2014. p. 241-61.

16. Vilarinho MV, Padilha MI. Feeling reported by health workers when facing the AIDS epidemic (19862006). Texto Contexto Enferm. 2016;25(1):1-9. doi: 10.1590/0104-07072016000010013

17. Ayres JRCM, Calazans GJ, Saletti Filho HC, Franca Junior I. Risco, vulnerabilidade e práticas de prevenção e promoção da saúde. In: Campos GW, Bonfim JRA, Minayo MCS, Carvalho YM, organizadores. Tratado de saúde coletiva. Rio de Janeiro: Fiocruz; 2006. p. 375-417. 
18. Salgado AWAP. A tatuagem e a Amazônia: uma reflexão sobre os símbolos amazônicos, comunicação e pintura corporal. RUTA Comunicación [Internet]. 2015 [acesso em 2019 nov 10];(6):1-9. Disponível em: https://www.raco.cat/index.php/Ruta/article/view/292048

19. Quadros KN, Campos CR, Soares TE, Silva FMR. Perfil epidemiológico de idosos portadores de HIV/AIDS atendidos no serviço de assistência especializada. Rev Enferm Cent Oeste Min. 2016; 6(2):2140-6. doi: https://doi.org/10.19175/recom.v6i2.869

20. Corstjens PLAM, Abrams WR, Malamud D. Saliva and viral infection. Periodontol 2000. 2016; 70:93110. doi: https://doi.org/10.1111/prd.12112

21. Villela WV, Barbosa RM. Prevention of the heterosexual HIV infection among women: is it possible to think about strategies without considering their reproductive demands? Rev Bras Epidemiol. 2015;18 Suppl 1:131-42. doi: 10.1590/1809-4503201500050010

22. Villela WV, Barbosa RM. Trajetória de mulheres vivendo com HIV/aids no Brasil. Avanços e permanências da resposta à epidemia. Ciênc Saúde Colet. 2017;22(1):87-96. doi:10.1590/141381232017221.14222016

23. Ferreira CO, Davoglio RS, Silva AA, Viana ASA, Rezende REA, Gomes AVTM. Perfil epidemiológico dos usuários de um centro de testagem e aconselhamento da Bahia. Rev Baiana Saúde Pública. 2016;40(2):388-409. doi: https://doi.org/10.22278/2318-2660.2016.v40.n2.a1980

24. Mafra RLP, Pereira ED, Varga ID, Mafra WCB. Aspectos de gênero e vulnerabilidade ao HIV/aids entre usuários de dois dos serviços de atendimento especializado em DST/aids de São Luís, Maranhão. Saúde Soc. 2016;25(3):641-51. doi: https://doi.org/10.1590/s0104-129020162580

25. Villela WV, Monteiro S. Gênero, estigma e saúde: reflexões a partir da prostituição, do aborto e do HIV/AIDS entre mulheres. Epidemiol Serv Saúde [Internet]. 2015 [acesso em 2018 out 30];24(3):531-40. Disponível em: http://www.scielo.br/pdf/ress/v24n3/2237-9622-ress-24-03-00531.pdf

26. Fernandes ER. Luxúria e selvageria na invenção do Brasil: enquadramentos coloniais sobre as sexualidades indígenas. Fronteiras [Internet]. 2016 [acesso em 2019 ago 10];18(32):239-67. Disponível em: http://ojs.ufgd.edu.br/index.php/FRONTEIRAS/article/view/5836

27. Silva TQC, Szapiro AM. Mulheres heterossexuais em relacionamento estável: limites do aconselhamento em DST/HIV/Aids. Rev Subj [Internet]. 2015 [acesso em 2020 fev 15];15(3):350-61. Disponível em: http://pepsic.bvsalud.org/scielo.php?script=sci_arttext\&pid=S2359-07692015000300004

28. Brilhante AVM, Moreira GAR, Vieira LJES, Catrib AMF. Um estudo bibliométrico sobre a violência de gênero. Saúde Soc. 2016;25(3):703-15. doi: https://doi.org/10.1590/s0104-12902016148937

29. Pereira ER, Oliveira LSS, Ito LC, Silva LM, Schmitz MJM, Pagliaro H. Sexual and reproductive health and sociocultural aspects of indigenous women. Rev Bras Promoç Saúde [Internet]. 2014 [acesso em 2018 
23 | Nóbrega RG, Oliveira NA, Lima EAR, Silva ACO, Almeida SA, Nogueira JA

out 15];27(4):445-54. Disponível em: https://periodicos.unifor.br/RBPS/article/view/2829/pdf_1

Fomento / Agradecimento: Conselho Nacional de Desenvolvimento Científico e Tecnológico (CNPQ). Edital Universal Processo 480129/2013-4, Processo 311371/2015-9.

\section{Autor correspondente}

Édija Anália Rodrigues de Lima.

E-mail: edijaprof@hotmail.com.

Endereço: R. Olívia do Nascimento Silva, n ${ }^{\circ}$ 55. Bancários. João Pessoa-PB. Brasil.

CEP: 58051-596.

\section{Contribuições de autoria:}

1 - Rafaela Gerbasi Nóbrega

Concepção do estudo e interpretação dos dados.

\section{2 - Natalia Aparecida de Oliveira}

Análise dos dados e revisão final com participação crítica e intelectual no manuscrito.

\section{3 - Édija Anália Rodrigues de Lima}

Análise dos dados e revisão final com participação crítica e intelectual no manuscrito.

\section{4 - Ana Cristina de Oliveira e Silva}

Análise e interpretação dos dados.

\section{5 - Sandra Aparecida de Almeida}

Análise e interpretação dos dados.

\section{6 - Jordana de Almeida Nogueira}

Concepção do estudo, análise dos dados e revisão final com participação crítica e intelectual no manuscrito.

\section{Como citar este artigo}

Nóbrega RG, Oliveira NA, Lima EAR, Silva ACO, Almeida SA, Nogueira JA. Prevenção do HIV sob o olhar de mulheres indígenas potiguaras. Rev. Enferm. UFSM. 2020 [Acesso em: Anos Mês Dia]; vol.10 e64: 1-23. DOI:https://doi.org/10.5902/2179769241396 